\title{
Design and Simulation of a Railway Vehicle for the Transport of People with Reduced Mobility
}

\author{
Nicola Bosso $(\mathbb{D}$, Antonio Gugliotta $(\mathbb{D}$, and Nicolò Zampieri $(i)$ \\ Department of Mechanical and Aerospace Engineering, Politecnico di Torino, Corso Duca degli Abruzzi 24, 10129 Torino, Italy \\ Correspondence should be addressed to Nicola Bosso; nicola.bosso@polito.it
}

Received 13 July 2017; Revised 13 December 2017; Accepted 8 January 2018; Published 14 February 2018

Academic Editor: Georges Kouroussis

Copyright (C) 2018 Nicola Bosso et al. This is an open access article distributed under the Creative Commons Attribution License, which permits unrestricted use, distribution, and reproduction in any medium, provided the original work is properly cited.

\begin{abstract}
One of the most important aspects of the design activity of passenger railway vehicles is the optimization of the comfort level that is often in contrast with other requirements, such as low weight, to reduce energy consumption, and high and flexible seating capacity. Due to the coach weight reduction, the car body structure becomes more susceptible to structural vibrations that affect the passenger comfort. In modern vehicles, seats are important elements to achieve the desired comfort, but in order to design and estimate the actual comfort level, the whole system must be considered, including the track excitations, a vehicle detailed dynamic model, and the coach and the seat flexibility. This paper describes a numerical model of a double-deck vehicle developed using a MB code that considers measured track irregularities, a detailed vehicle model, and a transfer function of the seat obtained by experimental tests on an optimized seat. In order to make the numerical model more realistic, the coach has been modeled as a flexible body to consider the effect of its natural frequencies. The work has been performed within the "CARITAS" project, whose aim is the design of a high comfort vehicle for people with reduced mobility.
\end{abstract}

\section{Introduction}

One of the most important aspects of a railway vehicle is to guarantee a high comfort level, especially if the vehicle is used for the transportation of people with reduced mobility. In general, the comfort can be defined as a physical and psychological condition of wellness, which is affected by many factors, such as vibrations, noise, temperature, and humidity. Regarding the dynamics of railway vehicles, the factors that are investigated and analyzed during the design of the vehicle are the ride comfort and the noise. The first one is affected by the mechanical vibrations of the vehicle with a frequency range from $0 \mathrm{~Hz}$ to $50 \mathrm{~Hz}$ [1]. Noise level in the coach is instead mainly affected by vibrations with a frequency range between $30 \mathrm{~Hz}$ and $5000 \mathrm{~Hz}$.

The evaluation of the vehicle comfort is usually performed by means of multibody simulations, where the coach is modeled as a rigid or a flexible body. The first solution [2,3] allows faster simulations but neglects the coach flexibility that can affect the ride quality of the vehicle. In the last years, more lightweight carbodies have been developed with the purpose to reduce the axle-load and to increase the energetic performance of the vehicle. The mass reduction results in larger structural vibrations in the frequency range where the human body shows greater sensitivity $[4,5]$. For this reason, several models considering a flexible coach have been developed. Two different approaches have been proposed: the first one considers the coach as an Euler-Bernoulli beam with uniformly distributed mass [5-7], while the second one considers the full coach FEM model, which is imported in the $\mathrm{MB}$ environment by superposing free-body modal modes [1, 8-12]. The first approach is able to simulate the flexibility of the coach structure but does not consider the local deformations due to the variation of mass and elastic properties. The second method, instead, allows considering this effect and so it is suitable when it is necessary to consider the vibrations of the floor, which have an important role in the coach acceleration, as demonstrated in [1]. The results of those studies demonstrate that the coach flexibility affects the estimation of the comfort index. Their limitation is based on the fact that the comfort estimation is made on the floor, neglecting the influence of the seat.

Another important component for the achievement of the vehicle comfort level is the seat $[13,14]$. This one is 
not usually directly modeled in the $\mathrm{MB}$ environment but its effect is accounted by filtering the floor acceleration by means of the weighting functions provided by regulations or standards [15]. The simulation of the effect of the seat on the comfort level can be performed using detailed FEM models [16], bus mostly a transfer function of the seat response is adopted [17]. This procedure is commonly adopted in the automotive field where a specific "Seat" index has been defined to account for the effect of the seat on the comfort estimation [18]. This procedure has been extended in general and a weighting function to account for the seat contribution is also introduced in the most recent standards [15]. However, the approach based on the use of a generic seat weighting function does not allow addressing the design of innovative and high comfort seats. This result can be only obtained considering the effect of the specific seat being designed, and in the railway field studies in this direction are mainly addressed to the study of the driver's seat [19]. In [20, 21], the authors describe a procedure and a test device that allow characterizing a passenger railway seat in order to simulate its behavior in the frequency domain and to obtain a specific transfer function that will be used in this work to describe the seat response to excitation.

This paper focuses on the ride comfort of a trailed doubledeck vehicle, which has been derived from the "Vivalto" coach used in Italy for regional service, and it is equipped with the Siemens SF400 bogies. The vehicle has a tare weight of 50 tons and a maximum operating speed of $160 \mathrm{~km} / \mathrm{h}$. The coach has been improved with respect to the original one in order to be suitable for the transportation of people with reduced mobility.

The design activity has been developed within the CARITAS project in the "Industria 2015" national research program. The main goal of the project is the design, construction, and testing of a functional prototype for an innovative double-deck wagon devoted to extended users, ensuring a safe and comfortable travel.

The present work describes the vehicle numerical model that has been built in order to analyze the ride comfort of the vehicle in different operative conditions when running on track. The model of the track considers the track irregularities (lateral, vertical, gauge, and roll) that are simulated using both the stochastic polynomials defined by the ORE B176 report [22] and the irregularities measured on the track. The vehicle is modeled with high level of details in order to obtain realistic results in terms of acceleration on the coach and very similar to the ones that occur on the real vehicle. Since the numerical model is used to optimize the vehicle performance in terms of comfort, the coach is modeled as a flexible body in order to take into account its natural frequencies, which affects the acceleration perceived by the passenger. In particular, the numerical model is able to evaluate the vibration of the coach floors and include the model of the seat. The results of the simulations are analyzed and used to evaluate the ride quality index of the vehicle according to the ISO 2631 standard [15]. This analysis is essential to predict the vibration level of the vehicle in different conditions when running on track. The results of the model allow us to optimize the characteristics of the first and secondary suspension and the coach structure

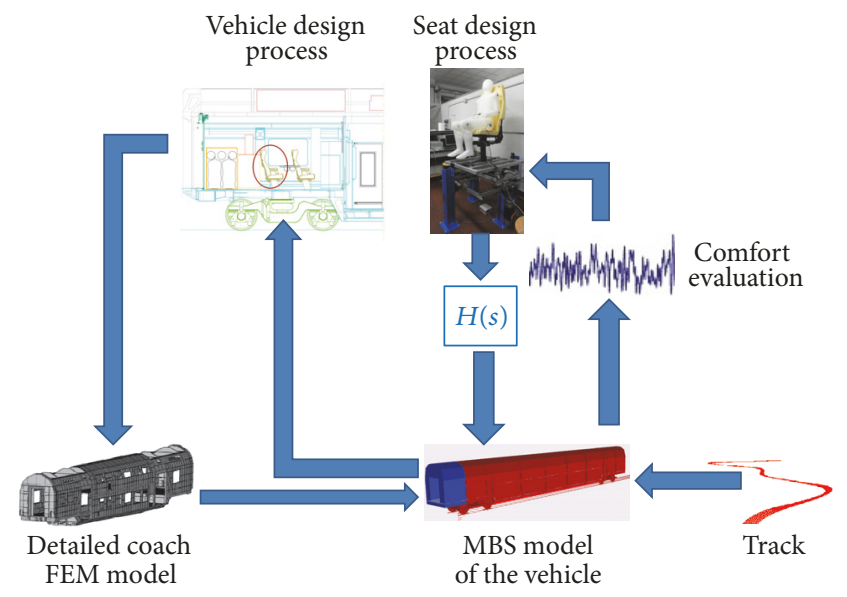

FIGURE 1: Scheme describing the function of the vehicle numerical model inside the design process.

and to evaluate the positions of the coach where the quality index is higher. Furthermore, during the activity related to the project, the characteristic of the seats (foam, structure) has also been optimized $[20,21]$ in order to achieve the best comfort attitude for the specific track and vehicle.

The novelty of this approach is shown in Figure 1, where the design process is schematically described: the multibody model has been developed to evaluate the comfort level of the vehicle during the design process and to take the design decisions, evaluating the vehicle behavior before its operation. Only if the entire system (track, vehicle, flexibility, and seat) is considered, the result of the simulation ensures that the target of the design can be achieved. This is especially important when considering people with reduced mobility whose comfort needs to be estimated considering the seat.

\section{Numerical Model of the Vehicle}

This section describes the numerical model of the vehicle developed with the Simpack 9.7 software. The model consists of three main submodels: the bogie model, the flexible coach, and the track.

2.1. The Bogie Model. The vehicle is equipped with the Siemens SF 400 bogies, which have been designed for pushpull service in passenger coaches. A drawing of the bogie is shown in Figure 2. The bogie maximum operational speed is $280 \mathrm{~km} / \mathrm{h}$.

The bogie model includes the following bodies: 2 wheelsets, 4 axle-boxes, the bolster, the bogie frame, the central leverage of the Watt linkage (used for the trailing system), and the antiroll bar (modeled as two separate bodies).

The contact between wheels and rails has been implemented by using the "General Rail Track Joint" of the Simpack library. This type of joint allows 6 d.o.f to the wheelset. The axle-box is connected to the wheelset by using a revolute joint that allows only the relative rotation of the two bodies around the wheelset axis. The bogie frame disposes of 

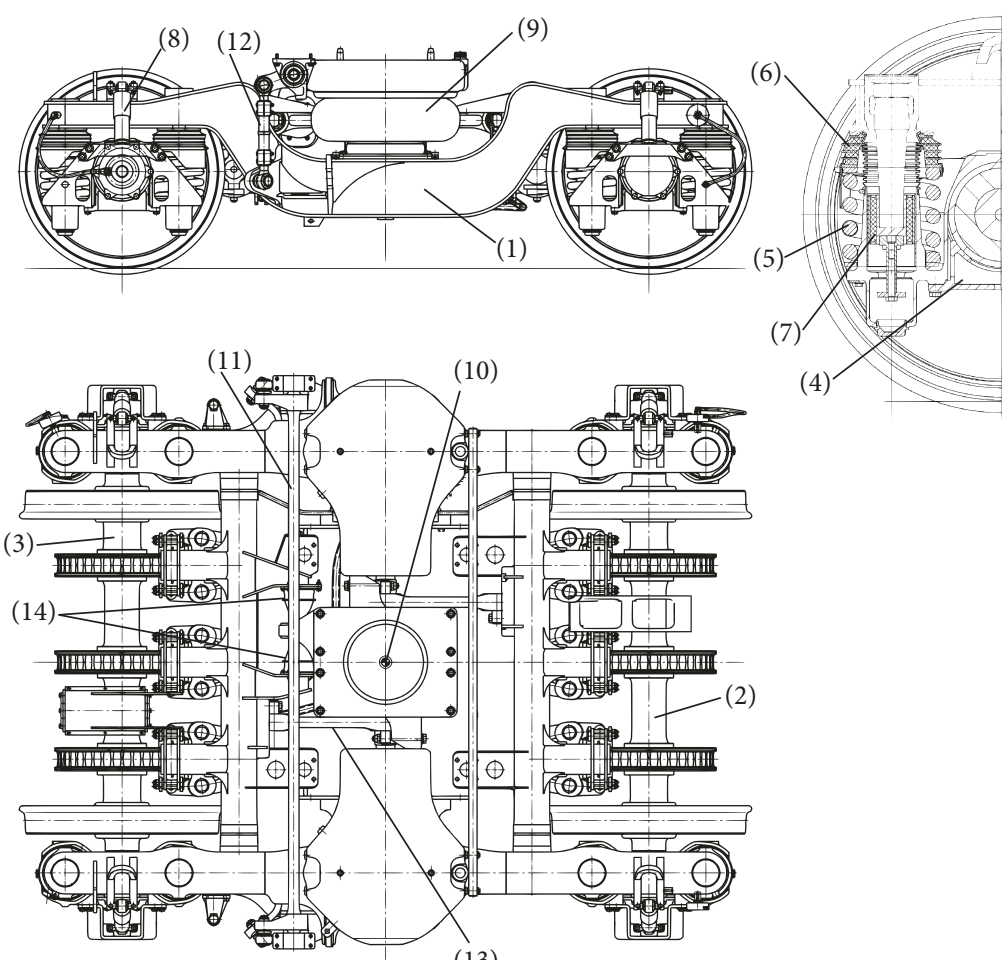

(13)
(1) Bogie frame
(2) Front wheelset
(3) Rear wheelset
(4) Axle-box
Primary suspension:
(5) Helical springs
(6) Top rubber element
(7) Bushing
(8) Primary damper

Secondary suspension:

(9) Air spring

(10) Centre pivot

(11) Anti-roll bar

(12) Anti-roll bar link

(13) Traction rod

(14) Lateral bump stop

FIGURE 2: SF400 Bogie technical drawing, courtesy of Magliola s.p.a leading the CARITAS project.

all the six d.o.fs and it is connected to the wheelsets by means of the primary suspension. Each bogie is then connected to the respective bolster through the secondary suspension. The bolster is connected to the wagon by using a bushing element, with six high stiffness components. This element is used to simulate a "quasi" rigid connection and takes into account the deformations of the bolster due to the load.

The Primary Suspension. The primary suspension level, used to connect the axle-boxes to the wheelset, is composed of three different mechanical parts (the number of elements is relative to each axle-box):

\section{(i) Two coil compression springs (Flexicoil)}

(ii) Two bushes used as axle-boxes guides and concentric to the coil springs

(iii) One damper

The coil springs (number (5) in Figure 2) have the peculiarity to be in series with two rubber elements (number (6) in Figure 2), which have a precise stiffness value along the three directions; see Table 2. These rubber elements are located at the top of the spring.

The equivalent stiffness $k_{\text {eq }}$ of the coil spring and the rubber elements can be calculated, in each direction, according to (1), which is implemented according to the Simpack "Flexicoil spring," where $k_{\mathrm{spr}}$ is the stiffness of the helical spring, $k_{\text {rub, } 1}$ is the stiffness of the rubber element at the top, and $k_{\mathrm{rub}, 2}$ is at the bottom of the spring. The considered bogie, as shown in Figure 3, has only a rubber element on the top of the spring; therefore, $1 / k_{\mathrm{rub}, 2}=0$.

$$
k_{\mathrm{eq}}=\frac{1}{1 / k_{\mathrm{rub}, 1}+1 / k_{\mathrm{spr}}+1 / k_{\mathrm{rub}, 2}} .
$$

The geometrical and material properties of the helical spring are reported in Table 1, while Table 2 shows the stiffness components of the rubber element.

In order to allow a displacement of the wheelset with respect to the bogie frame in the lateral and longitudinal direction, the SF400 bogie is equipped with axle-box guides (number (7) in Figure 2). These elements are very important 


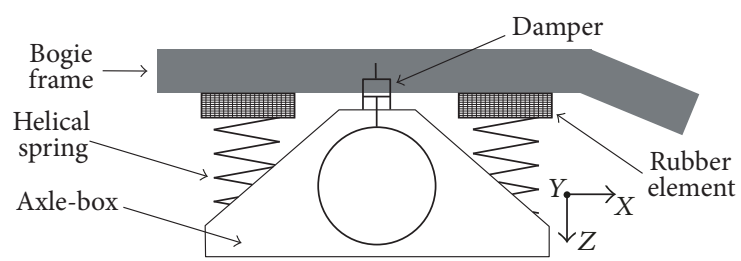

FIGURE 3: Primary suspension scheme of the rubber element located at the extremity of the helical spring.

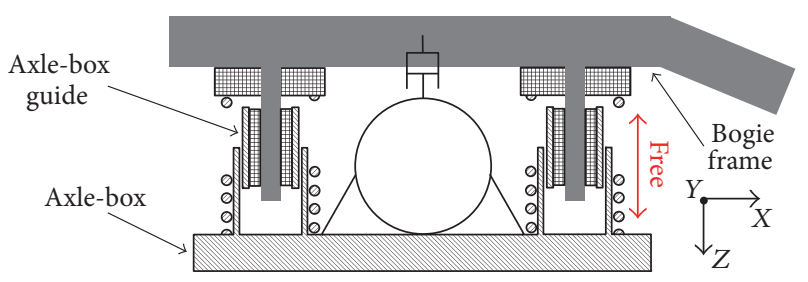

FIgURE 4: Detail of the axle-box guide system of the primary suspension.

TABLe 1: Properties of the helical spring.

\begin{tabular}{lcc}
\hline Geometrical characteristics & Value & Units \\
\hline Nominal height of helical spring & 0.234 & $\mathrm{~m}$ \\
$d$, diameter of Wire & 0.036 & $\mathrm{~m}$ \\
rf, radius of spring & 0.2047 & $\mathrm{~m}$ \\
$n$, number of turns & 3.5 & - \\
$h 0$, unloaded height & 0.2806 & $\mathrm{~m}$ \\
\hline
\end{tabular}

TABLE 2: Stiffness of the rubber elements located at the top of the spring.

\begin{tabular}{lcc}
\hline Stiffness components & Value & Units \\
\hline Radial stiffness $x$ direction & 250000 & $\mathrm{~N} / \mathrm{m}$ \\
Radial stiffness $y$ direction & 250000 & $\mathrm{~N} / \mathrm{m}$ \\
Axial stiffness $z$ direction & 3500000 & $\mathrm{~N} / \mathrm{m}$ \\
Bending stiffness $x$-axis & 100000000 & $\mathrm{Nm} / \mathrm{rad}$ \\
Bending stiffness $y$-axis & 100000000 & $\mathrm{Nm} / \mathrm{rad}$ \\
\hline
\end{tabular}

TABle 3: Stiffness of the axle-box guide.

\begin{tabular}{lcc}
\hline Stiffness components & Value & Units \\
\hline Transl. stiffness cx & 24300000 & $\mathrm{~N} / \mathrm{m}$ \\
Transl. stiffness cy & 5500000 & $\mathrm{~N} / \mathrm{m}$ \\
\hline
\end{tabular}

for the vehicle dynamics especially when the vehicle is negotiating the curve. Figure 4 shows a scheme of the axle-box guide, which allows free movement in the vertical direction $z$ but acts along the $x$ and $y$ directions.

The guide is modeled using a bushing element connecting the axle-box and the bogie frame. Table 3 shows the values of the stiffness components of this element; the component of stiffness in the $z$ direction is equal to $0 \mathrm{~N} / \mathrm{m}$, since the element is free to move along this direction.

The damping of the primary suspension is provided by a hydraulic damper on each axle-box (number (8) in Figure 2).

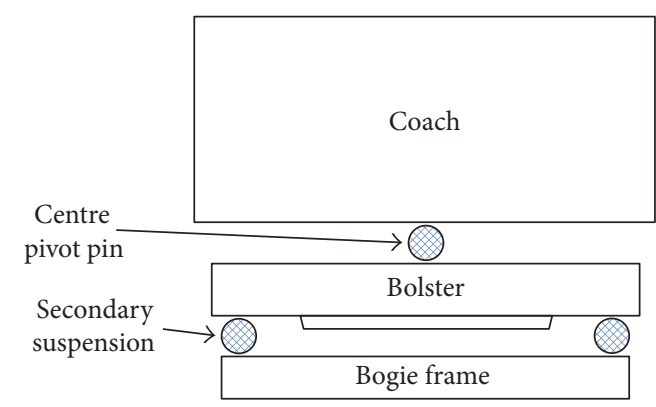

FIGURE 5: Scheme of the secondary suspension.

TABLE 4: Stiffness components of the air spring.

\begin{tabular}{lcc}
\hline Stiffness components & Value & Units \\
\hline Transl. stiffness c_x & 140000 & $\mathrm{~N} / \mathrm{m}$ \\
Transl. stiffness c_y & 140000 & $\mathrm{~N} / \mathrm{m}$ \\
Transl. stiffness c_z & 300000 & $\mathrm{~N} / \mathrm{m}$ \\
Transl. damping d_x & 1000 & $\mathrm{Ns} / \mathrm{m}$ \\
Transl. damping d_y & 1000 & $\mathrm{Ns} / \mathrm{m}$ \\
Transl. damping d_z & 6500 & $\mathrm{Ns} / \mathrm{m}$ \\
\hline
\end{tabular}

This element is installed between the bogie frame and the axle-box with an angle with respect to the vertical direction in order to obtain a damping effect in both the lateral $y$ and vertical $z$ direction. The damper is modeled using a point to point force element, whose characteristic is provided by means of an input function. The damper has a damping coefficient equal to $10000 \mathrm{Ns} / \mathrm{m}$.

The Secondary Suspension. The secondary suspension has the function to connect the bogie frame and the wagon. In the numerical model, the secondary suspension links the bogie frame and the bolster which is then linked to the coach by using a more rigid element, in order to simulate the connection stiffness of these elements. In the real vehicle, the bolster is rigidly connected to the coach structure. The secondary suspension is composed of the following elements:

\section{(i) Two air springs \\ (ii) two vertical dampers}

The vehicle has two air springs (number (9) in Figure 2), on each bogie, one on the left and one on the right side of the bolster; see Figure 5. These elements are modeled using the nonlinear air spring element included in the Simpack library. Table 4 shows the adopted values of stiffness and damping of the air spring.

In addition to the damping effect introduced by the air spring, the secondary suspension includes two vertical hydraulic dampers with a damping coefficient equal to $10000 \mathrm{Ns} / \mathrm{m}$

The Antiroll System. The vehicle, developed in the project, disposes of an antiroll system composed of the antiroll bar (number (11) in Figure 2), free to rotate around its axis with respect to the bolster, and two links (number (12) in Figure 2), 
TABle 5: Properties of the antiroll bar.

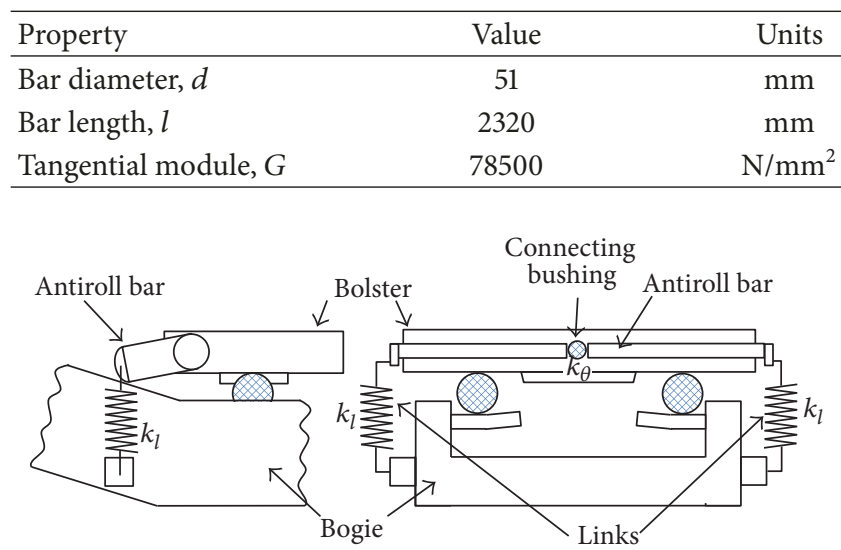

FIgURE 6: Antiroll system adopted for the vehicle.

which are used to connect the extremities of the antiroll bar to the bogie frame. In order to keep into account the torsional stiffness of the antiroll bar, this has been modeled using two bodies connected to each other by means of a bushing element; see Figure 6 . The torsional stiffness $k_{\theta}$ of the bar can be calculated according to

$$
k_{\theta}=\frac{G \pi d^{4}}{32 l}=22473 \mathrm{Nm} / \mathrm{rad} .
$$

Table 5 shows the values of the quantities used in (2).

The mass of the links has been neglected and they have been modeled as point to point forces applied at the extremities of the antiroll bar. The stiffness of the link is calculated as the series of the link stiffness and the stiffness of the elastic connections between the bolster and the antiroll bar. The value of the equivalent stiffness $\left(k_{l}\right)$ is equal to $55 * 10^{6} \mathrm{~N} / \mathrm{m}$.

The Trailing System. The trailing system can influence the comfort level of the passengers, especially during the acceleration/deceleration operations of the vehicle. Figure 7 shows the trailing system adopted for the vehicle, based on Watt's linkage.

The trailing system is composed of the central leverage that is free to rotate around the $z$-axis and the two traction rods (number (4) in Figure 8) disposed symmetrically to the longitudinal axis. These elements connect the central leverage to the bogie frame. The central leverage is modeled as a single body connected to the bogie frame by means of a revolution joint around the $z$-axis. The traction rods are modeled as spring-damper parallel force elements. The real vehicle includes an elastic element placed on the pivot of the central leverage (number (6) in Figure 8) that is modeled considering its stiffness in series with the stiffness of the elastic elements of the articulated joints of the traction rods (number (5) in Figure 8). Therefore, the equivalent stiffness of each traction rod can be determined from

$$
k_{\mathrm{eq}}=\frac{1}{1 / k_{j 1}+1 / 2 k_{\mathrm{spr}}+1 / k_{\mathrm{j} 2}}=111000 \mathrm{~N} / \mathrm{m} \text {. }
$$

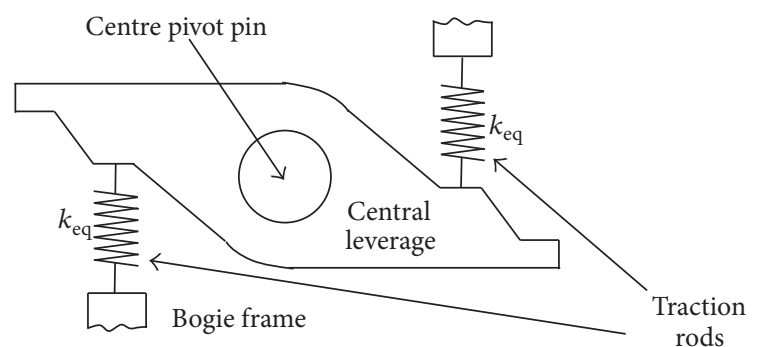

FIGURE 7: Schematics of Watt's trailing system.

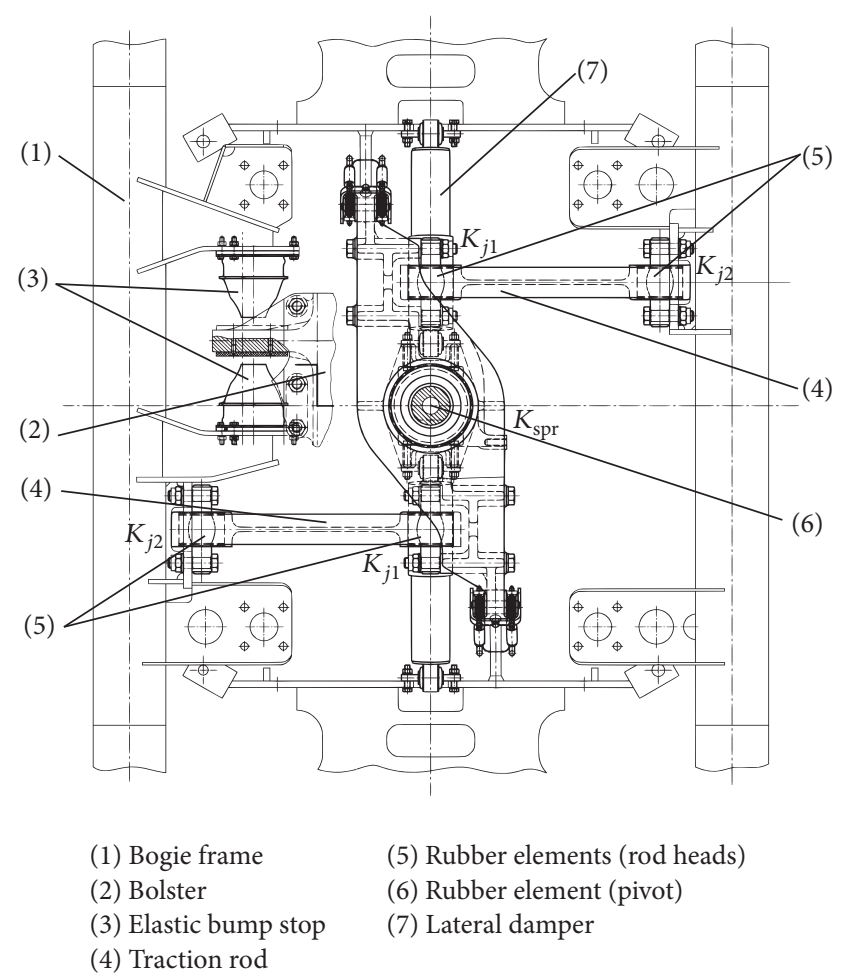

FIGURE 8: Detail of the bump stops used to limit the coach lateral displacement and of the traction system.

TABLE 6: Stiffness values of the traction rod force element.

\begin{tabular}{lcc}
\hline Element & Value & Units \\
\hline Pivot spring & 75000000 & $\mathrm{~N} / \mathrm{m}$ \\
Articulated joint 1 & 250000 & $\mathrm{~N} / \mathrm{m}$ \\
Articulated joint 2 & 200000 & $\mathrm{~N} / \mathrm{m}$ \\
\hline
\end{tabular}

In (3) $k_{\text {spr }}$ is the stiffness of the pivot spring, $k_{j 2}$ is the stiffness of the articulated joint connecting the traction rod and the bogie, and $k_{j 1}$ is the stiffness of the articulated joint connecting the traction rod and the central leverage. Table 6 shows the stiffness values used, while Figure 8 shows the position of the elastic elements.

In order to take into account the hysteretic behavior of the rubber elements, a damping coefficient equal to $12400 \mathrm{Ns} / \mathrm{m}$ 


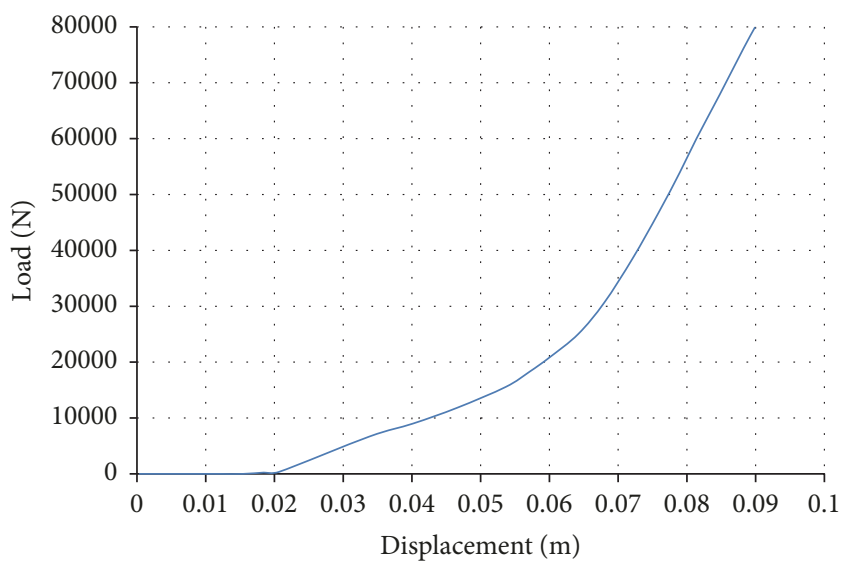

FIGURE 9: Force-displacement characteristic of the bump stop.

has been added to the force element that simulates the traction rod.

Transversal Actions. The transversal actions on the bogie are contained by the following elements:

(i) Two horizontal dampers connected between the bogie frame and the central leverage of Watt's articulation (number (7) in Figure 8)

(ii) Two lateral bump stops to limit the lateral displacement of the coach (number (3) in Figure 8)

The two horizontal hydraulic dampers are installed not parallel to the track plane in order to have a component of the damping force acting in the vertical direction $z$. The damping coefficient of the dampers is equal to $12500 \mathrm{Ns} / \mathrm{m}$. The two lateral bump stops have the shape of truncated cone with axis parallel to the lateral direction $y$ and are installed in opposition, as shown in Figure 8.

These elements enter in contact with the flat surface obtained on the bolster (number (2) in Figure 8) when the displacement of the coach is greater than $18 \mathrm{~mm}$. The bump stops are modeled using bushing elements with an input function that describes the characteristic force-displacement of the elastic element. Figure 9 shows this characteristic where it is possible to see that the elastic bump stop generates a force only when the displacement of the coach with respect to the bogie is greater than $18 \mathrm{~mm}$.

2.2. The "Flexible" Coach Model. This section shows the integration of the coach FEM model, realized using the Ansys software, in the vehicle MB model. The FEM model has been developed within the CARITAS project in order to optimize the coach structure in terms of mechanical strength and vibration level. The FEM model includes the first and second floor of the coach, fundamental for the analysis of the coach vibrations. In order to integrate the FEM model, it is necessary to add the master nodes to interface the coach flexible model with the Simpack MB model. The master nodes correspond to the points of the coach structure where multibody elements are connected,

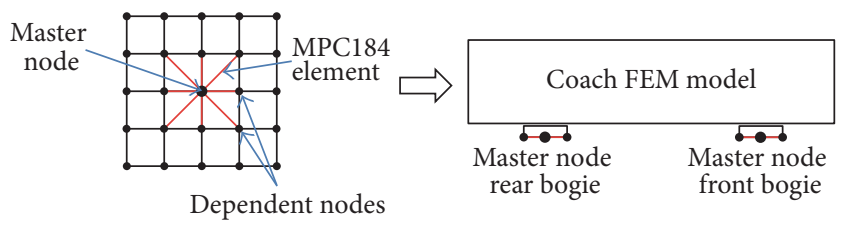

FIGURE 10: Connection of the mesh nodes near the master node with MPC184 elements.

such as joints, sensors, and forces. The standard MB approach considers rigid bodies and concentrates the force on a single point (marker). In order to distribute the load to the nodes close to the master node, it is necessary to include specific "interface" elements on the FEM model. For this reason, the Ansys MPC184 elements have been used to connect the mesh nodes near to a master node. MPC184 elements are twonode multipoint elements constraint that applies kinematic constraints between nodes; see Figure 10.

In this case, these elements are used as rigid beams in order to simulate a rigid connection between the nodes defining the element. In this way, the six d.o.fs of each node, connected to the master node by means of MPC184 elements, depend only on the d.o.fs of the master node. The kinematic constraints are imposed by means of the direct elimination method, which generates internal constraint equations with the aim of eliminating the degrees of freedom of a dependent node in favour of an independent node (master). The density of the MPC184 elements has been set to $0 \mathrm{Kg} / \mathrm{m}^{3}$ in order to have no mass elements that operate as internal constraints. In total, 8 master nodes have been defined: 2 nodes for the connection of the flexible coach with the bogies and 6 nodes for the connection of the seats to the coach floor. As regards the connection of the flexible coach to the bolster, the master node has been defined in the geometrical center of the interface area between the two bodies. Each node inside this area has been connected with a MPC184 element to the master node in order to make its d.o.fs dependent from the ones of the master node. The same approach has been adopted for the connection of the seat to the coach floor. The flexible carbody, imported in the MB environment, has been connected to the bolsters by using two bushings defined between the coach master node and the bolster center of mass. The marker on the flexible body has been defined as position connects and so its position and orientation agree with the one of the master node. All the translational and rotational stiffness components of the bushing element are equal to $10^{8} \mathrm{~N} / \mathrm{m}$ in order to simulate a rigid connection between the bolster and the coach; see Figure 11. The rotation and displacement of the coach with respect to the bogies are allowed by the secondary suspension which has been previously described.

In order to import the FEM model into Simpack, a substructure analysis has been performed and the result files containing the modal condensation (.sub), the model geometry (.cdb), and the recovery matrix (.tcms) have been used to generate the Simpack fbi file, which is the "modal super-element" to import inside the MB model. Figure 12 shows the complete multibody model with the flexible coach. 


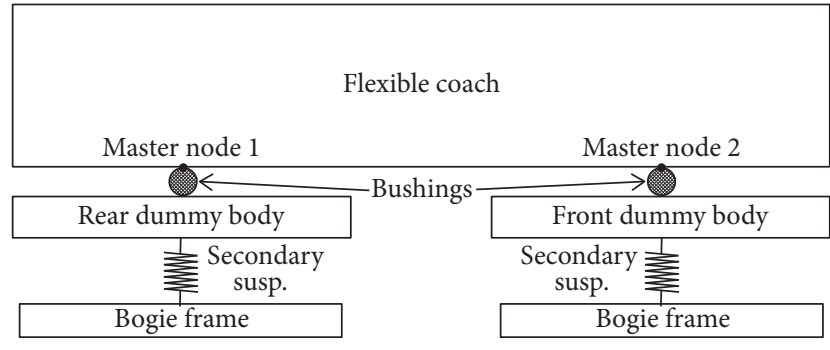

FIgURE 11: Connection of the flexible coach to the bolsters.

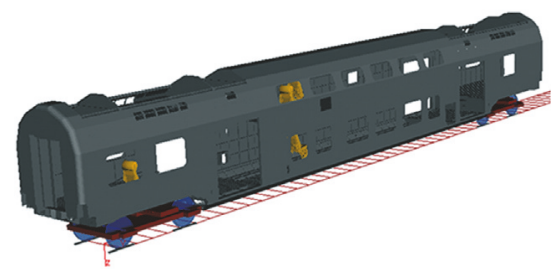

FIGURE 12: Complete multibody model of the vehicle with flexible coach.

TABLE 7: Natural frequencies of the coach lower than $20 \mathrm{~Hz}$.

\begin{tabular}{llc}
\hline Mode number & Mode type & Frequency $[\mathrm{Hz}]$ \\
\hline$(1)$ & $\begin{array}{l}\text { 1st coach torsional } \\
\text { Lower floor 1st vertical }\end{array}$ & 6.3 \\
bending & 8.06 \\
Upper floor 1st vertical & 9.08 \\
bending & 10.67 \\
1st coach vertical bending & 12.07 \\
Coach vertical bending and & torsional \\
(6) & $\begin{array}{l}\text { Lower floor 2nd vertical } \\
\text { Bending }\end{array}$ & 14.13 \\
Up & $\begin{array}{l}\text { bending } \\
\text { Coach and upper floor }\end{array}$ & 16.5 \\
$(8)$ & vertical bending & 19.5 \\
\hline
\end{tabular}

Table 7 shows the frequencies of the coach with a frequency value less than $20 \mathrm{~Hz}$. These ones correspond to the frequencies where the human body shows more sensibility since they are next to the natural frequencies of the organs. Figures 13 and 14 show, respectively, the fourth and the fifth natural frequency of the coach.

2.3. The Seat Model. Current legislation does not consider the effect of the seat on the comfort perceived by the passenger. The standards suggest measuring the acceleration at the floor level on different part of the vehicle and to use the acquired signals to calculate the comfort index. The choice of the standards is justified by the fact that it is also necessary to ensure a good level of comfort for standing passengers. The seat, being an additional suspension level between the coach floor and the passenger, affects the level of comfort perceived.

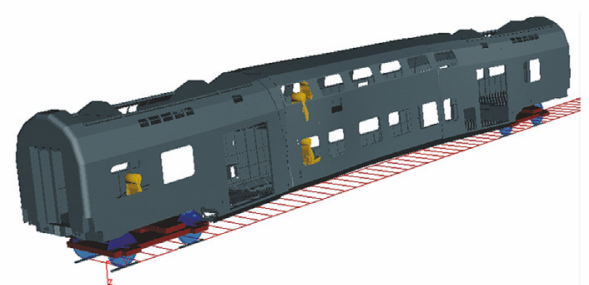

FIGURE 13: Modal shape of the 4th mode at $10.67 \mathrm{~Hz}$.

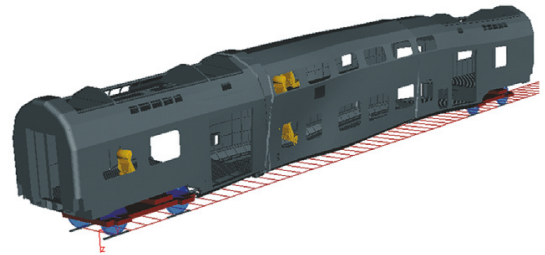

FIGURE 14: Modal shape of the 5th mode at $12.07 \mathrm{~Hz}$.

The seat is simulated as a single rigid body with a mass of $150 \mathrm{~kg}$ that takes into account the mass of the seat and the mass of a standard person. The seat is jointed to the coach by means of a 6 d.o.fs joint applied between the seat center of mass and a master node of the coach. The element force connecting the seat to the coach allows simulating components with frequency dependent behavior. This frequency dependent force element allows defining for each direction a transfer function describing the dynamic response of the seat in a specific direction. The transfer functions have been experimentally calculated by means of the railway seat test rig developed by the authors [20,21], after an optimization process to define the foam and structure characteristics. Figure 15 shows the transfer functions between the coach floor and the seat, which have been introduced in the Simpack frequency dependent force element.

2.4. The Track Model. The only model of the vehicle is not sufficient to evaluate the ride comfort index of the vehicle since it is necessary to simulate the track and the irregularities. The track considered in this work is from Peschici to S. Severo, located on the Gargano, Italy. The track is $78 \mathrm{~km}$ long and includes small radius curves and slopes greater than the $30 \%$. The layout of the track in the horizontal and vertical plane is shown in Figures 16 and 17, respectively.

Figure 18 shows the irregularities considered in the model, which have been modeled as rail related irregularities. They have been measured on the track during experimental tests.

2.5. Wheel-Rail Contact. The model has been realized using Simpack 2017, and the wheel-rail contact model has been simulated adopting the native flexible wheel-rail contact model [23], considering UIC 60 rail profiles canted $1: 20$, new S1002 wheel profiles with a radius of $460 \mathrm{~mm}$. The contact model consists of a wheel-rail contact joint allowing 6 degree of freedom to the wheelset (substantially unconstrained), an elastic element that represents the normal force that is able to 


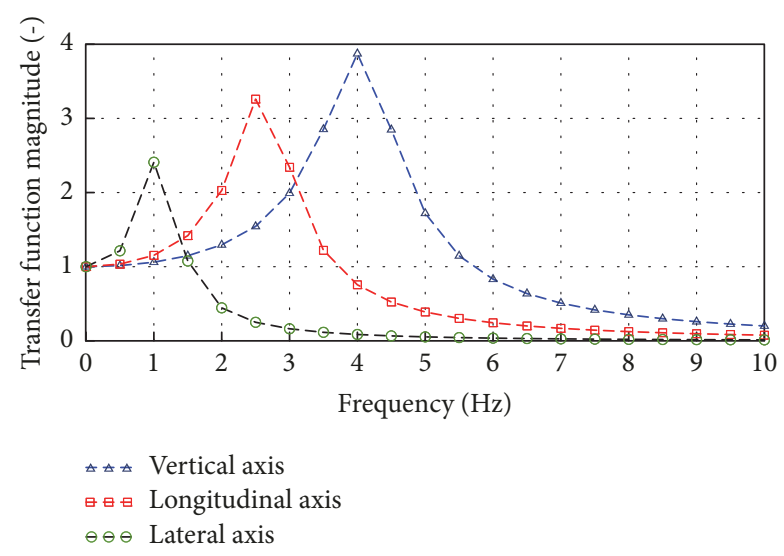

Figure 15: Transfer functions between the seat and the coach floor along the longitudinal, lateral, and vertical direction.

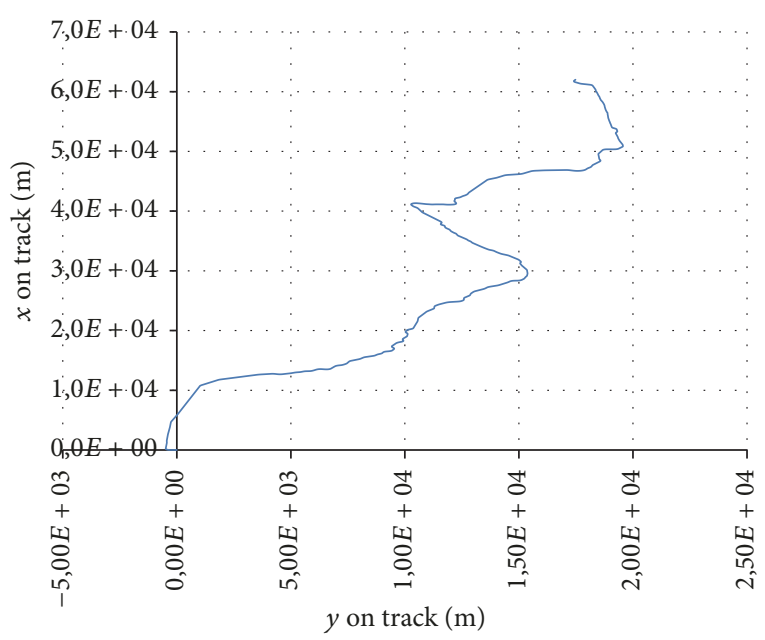

FIGURE 16: Layout of the track in the horizontal plane.

manage up to 5 simultaneous contact points (on straight track only one contact point is active), and a tangential friction force that arises due to the relative velocity between wheel and rail. The tangential force can be modeled according to different models commonly used in literature. In this work, the model based on the Fastsim algorithm [24] has been used. The friction coefficient between wheel and rail has been assumed as constant and equal to 0.4 .

\section{Sensors Position and Comfort Index Calculation}

This section describes the simulations performed to assess the vehicle quality index. In order to evaluate the comfort level, it is necessary to install sensors on the coach at the points as indicated by the standards. According to [15], the sensors have to be located at the floor level. In the numerical model, the following sensors have been positioned:

(i) On the ground floor over the bogies

(ii) On the ground floor in the middle of the coach

(iii) On the first floor in the middle of the coach

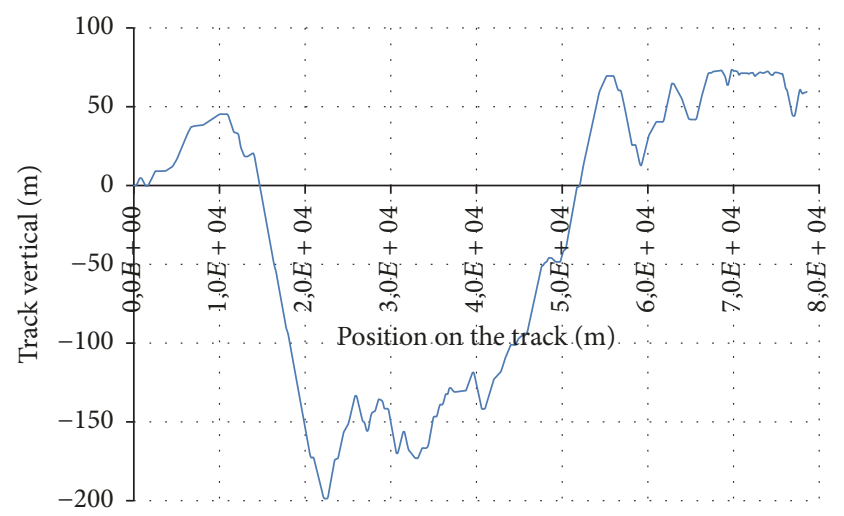

FIGURE 17: Layout of the track in the vertical plane.

The sensors used are those in the Simpack library and provide position, velocity, and acceleration of the marker to which they are connected. On the ground floor, 6 sensors are placed, 2 over the front bogie, 2 over the rear bogie (see Figure 19), and 2 in the central part of the coach (see Figure 20). The sensors over the bogies are placed over the bolster and outside from the pneumatic spring profile in order to not affect the measured acceleration.

In order to get a complete framework of the acceleration values on the coach, two sensors have been located on the upper floor. Figure 21 shows the position of these sensors.

In order to evaluate the effect of the seat on the passenger comfort additional sensors have been installed on this part.

The comfort index has been evaluated according to the ISO 2631-1:1997 standard [15], which provides the acceleration weighting indexes and defines a comfort index based on the RMS value of the acceleration (calculated in accordance with (4)).

$$
\mathrm{ISO}_{\text {index }}=\sqrt{\left(1.4 a_{x w d}\right)^{2}+\left(1.4 a_{y w d}\right)^{2}+a_{z w b}^{2}} .
$$

The ISO 2631 [15] and ISO 8041 [25] define four filters, defined in the frequency domain [26], that are used to build the weighting functions of the acceleration. The filters defined by the standard are the following equations:

High-pass filter:

$$
H_{h}=\frac{s^{2}}{s^{2}+\left(\omega_{1} / Q_{1}\right) s+\omega_{1}^{2}} \text {. }
$$

Low-pass filter:

$$
H_{l}=\frac{\omega_{2}^{2}}{s^{2}+\left(\omega_{2} / Q_{2}\right) s+\omega_{2}^{2}} .
$$

Acceleration-velocity transition filter:

$$
H_{t}=\frac{\left(\omega_{4}^{2} / \omega_{3}\right) s+\omega_{4}^{2}}{s^{2}+\left(\omega_{4} / Q_{4}\right) s+\omega_{4}^{2}}
$$




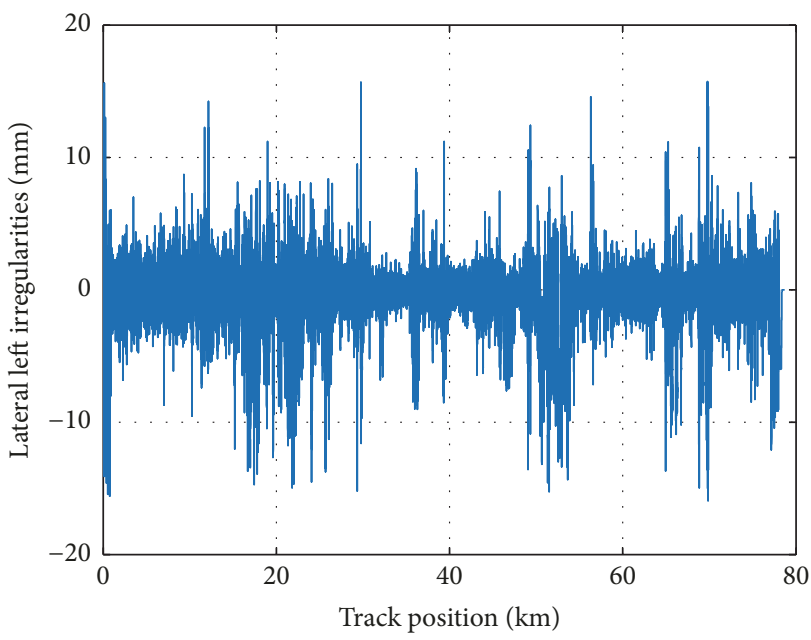

(a)

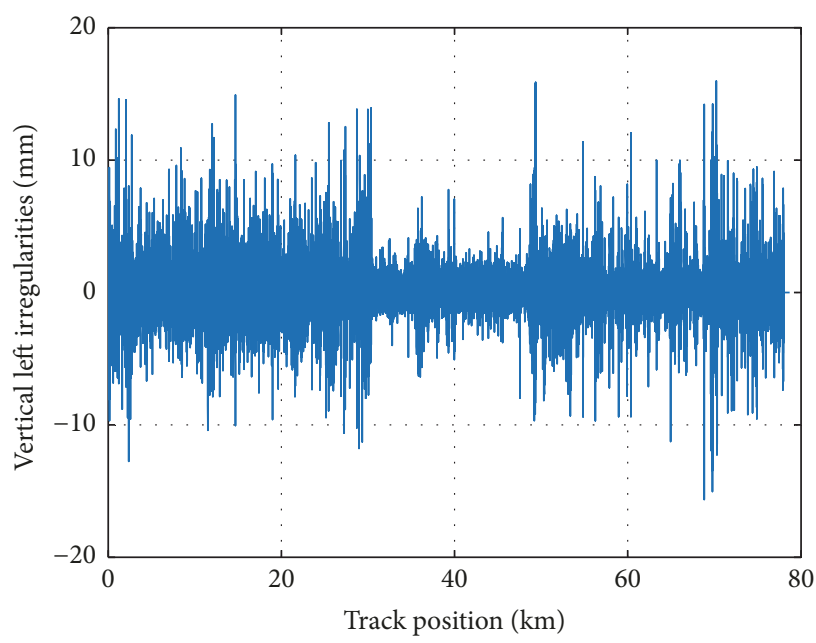

(c)

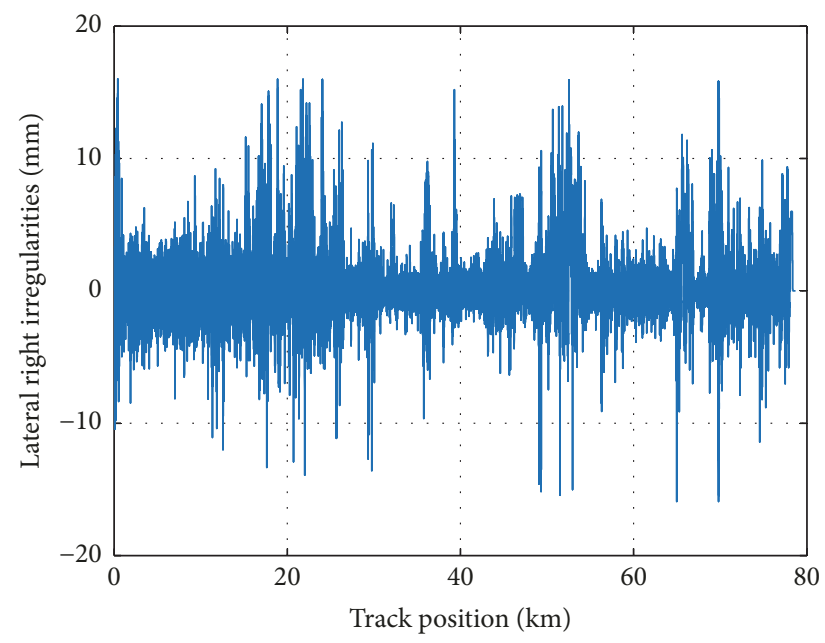

(b)

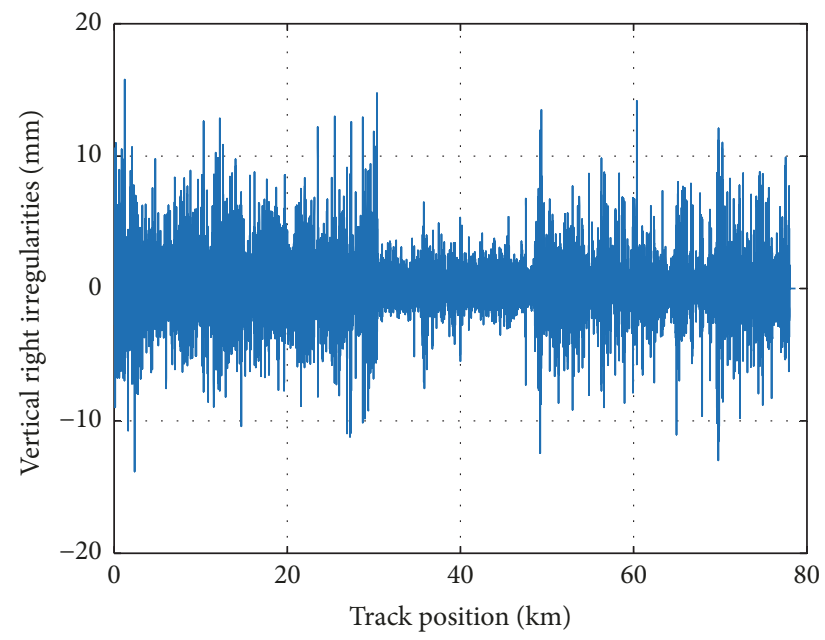

(d)

FIGURE 18: Measured track irregularities.

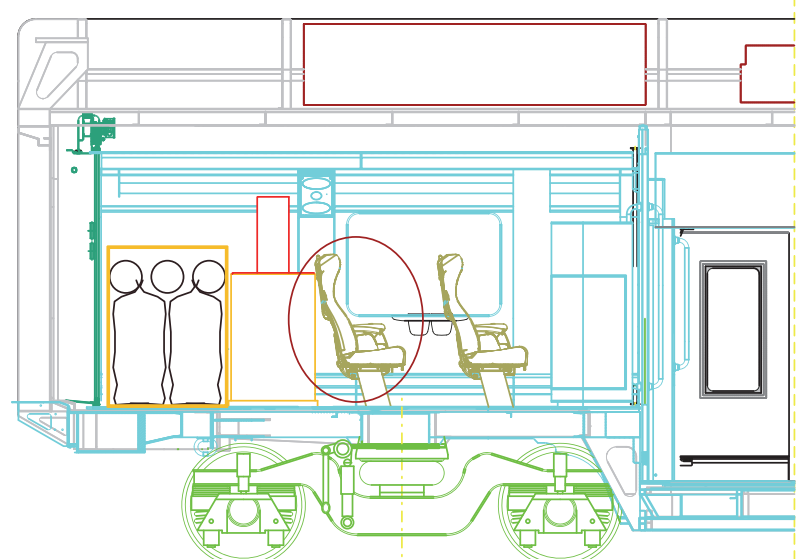

FIgURe 19: Position of the sensors (red circles) on the ground floor over the rear bogie.
Upward step filter:

$$
H_{s}=\frac{s^{2}+\left(\omega_{5}^{2} / Q_{4}\right) s+\omega_{5}^{2}}{s^{2}+\left(\omega_{6} / Q_{6}\right) s+\omega_{6}^{2}} .
$$

These indexes are combined with each other in order to calculate the weighting functions. The parameters that appear in (5)-(8) are taken from the ISO2631 and ISO8041 standards. The weighting function $H_{x y}$ for the acceleration in $x$ and $y$ direction is reported in (9), while the weighting function $H_{z}$ for the acceleration in $z$ (vertical) direction is shown in (10).

$$
\begin{aligned}
& H_{x y}=H_{h} H_{l} H_{t} \\
& H_{z}=H_{h} H_{l} H_{t} H_{s} .
\end{aligned}
$$

Once the acceleration has been weighted using the filters of (9) and (10), the RMS value of the acceleration is calculated using a time window of 5 seconds [27]. 


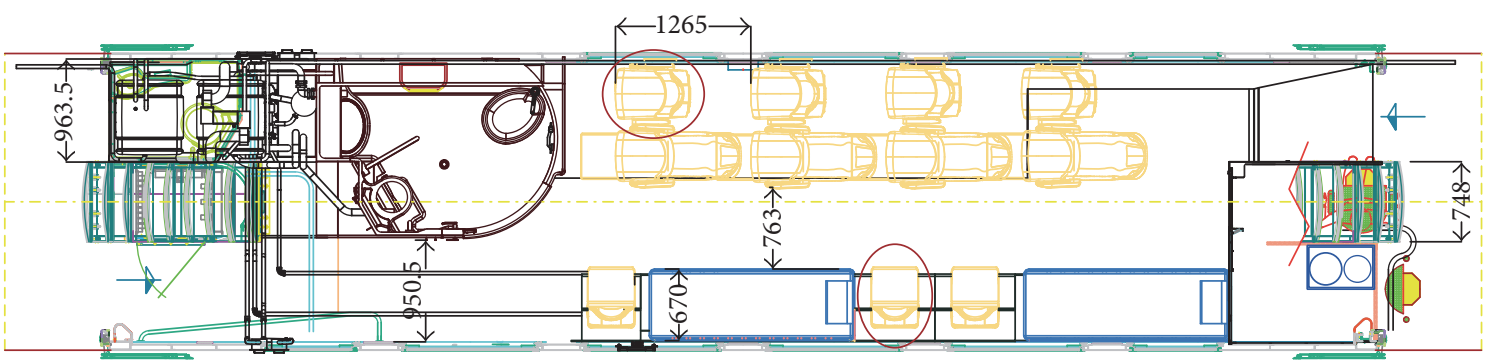

Figure 20: Position of the sensors (red circles) on the ground floor in the coach central part.

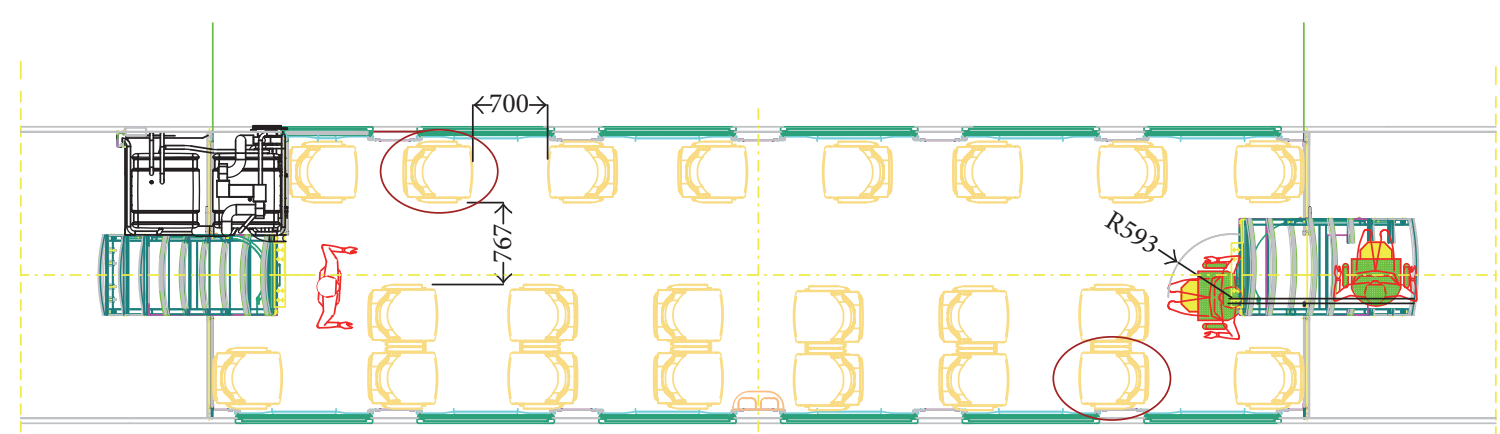

FIgURE 21: Position of the sensors (red circles) on the first floor.

TABLE 8: Limit values of the ISO coefficient (taken from [20]).

\begin{tabular}{lc}
\hline r.m.s. vibration level & Perception \\
\hline Less than $0.315 \mathrm{~m} / \mathrm{s}^{2}$ & Not uncomfortable \\
$0.315 \mathrm{~m} / \mathrm{s}^{2}$ to $0.63 \mathrm{~m} / \mathrm{s}^{2}$ & A little uncomfortable \\
$0.5 \mathrm{~m} / \mathrm{s}^{2}$ to $1 \mathrm{~m} / \mathrm{s}^{2}$ & Fairly uncomfortable \\
$0.8 \mathrm{~m} / \mathrm{s}^{2}$ to $1.6 \mathrm{~m} / \mathrm{s}^{2}$ & Uncomfortable \\
$1.25 \mathrm{~m} / \mathrm{s}^{2}$ to $2.5 \mathrm{~m} / \mathrm{s}^{2}$ & Very uncomfortable \\
Greater than $2 \mathrm{~m} / \mathrm{s}^{2}$ & Extremely uncomfortable \\
\hline
\end{tabular}

Obviously, it is not possible to directly compare the value of the ISO index to the perception of the passengers, but the standard indicates some values that can be used as a reference for assessing the comfort quality of a vehicle; see Table 8 .

The simulations have been performed running the vehicle on the track and considering the track irregularities. The vehicle speed has been imposed equal to the maximum allowed for the considered track. In order to control the vehicle speed, a traction force has been applied on the vehicle. The force is applied between the carbody and the main reference system along the $x$-axis. The marker on the main reference system is not fixed but moves with the vehicle on the track and so the traction force follows the track and it is always perpendicular to the track ( $x$-axis direction of the vehicle). Figure 22 shows the speed profile of the vehicle.

\section{Results}

This section shows the results obtained from the numerical model running on track. The simulations have been executed

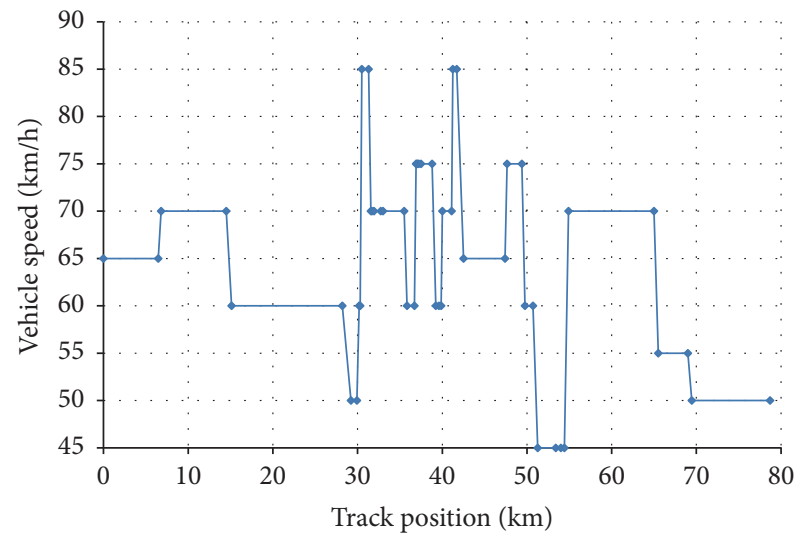

Figure 22: Speed profile of the vehicle during the simulations.

on an Intel Core i5-4670@3.40 GHz processor with 16 GB of RAM, which allows a real-time factor equal to 1.15 (simulation runs 1.15 times slower than real-time). This work analyzes the effect of considering a flexible coach on the comfort index calculation.

Figure 23 shows a comparison of the acceleration measured on the rigid and the flexible coach. Observing the results, it is evident that the coach flexibility more affects the vertical acceleration, especially on the upper floor and on the central ground floor, where several modes are excited by the track irregularities. Considering the lateral direction, the influence of the floor flexibility is less important, in fact, it is partially affected by the coach natural modes. In general, 

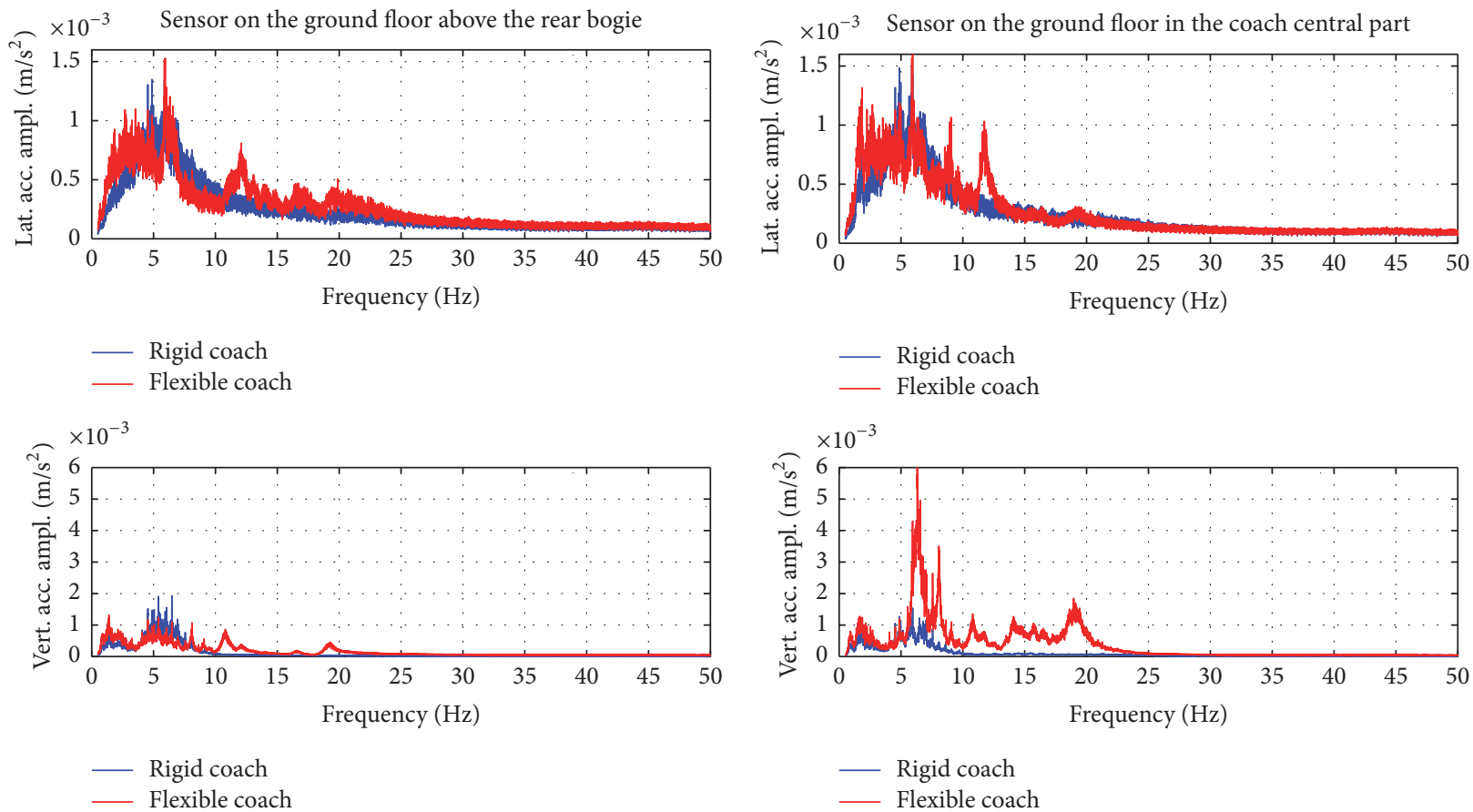

(a)

(b)
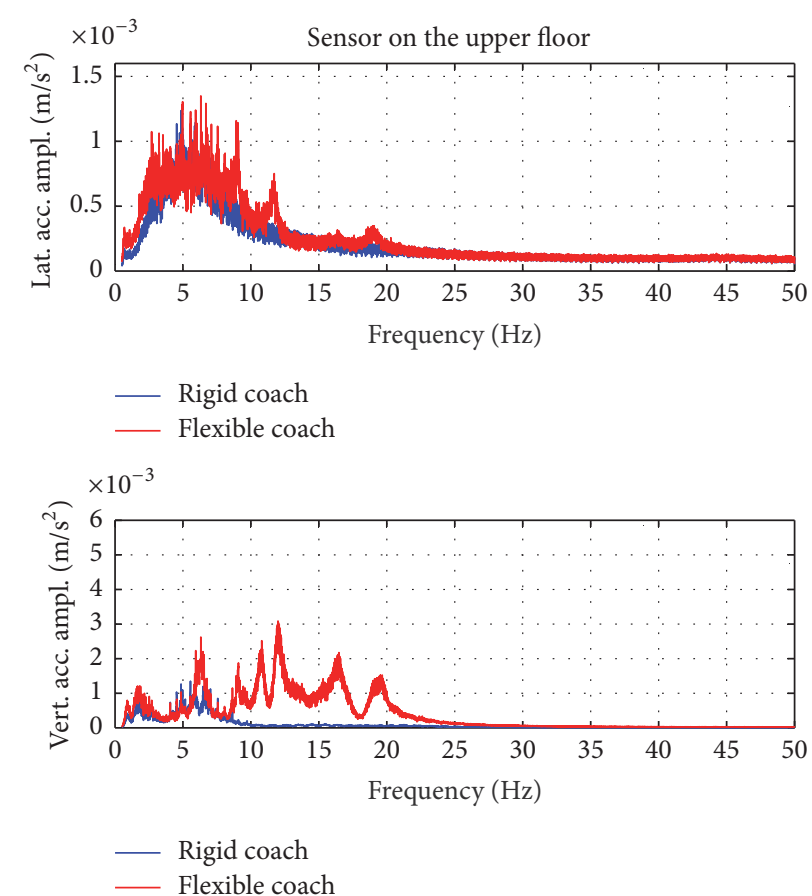

(c)

FIgURE 23: Amplitude of the lateral and vertical acceleration measured on different points of the coach.

the lateral acceleration is mainly affected by the bogie modes that are in the frequency range $0-7 \mathrm{~Hz}$. The longitudinal acceleration is not shown since this direction is not affected by the coach flexibility.

These assertions are confirmed by Figure 24 where the vehicle comfort index is compared when considering rigid and flexible coach. The comfort index is in fact affected by the coach flexibility only when considering the sensors installed on the upper floor and on the central part of the ground floor. The sensor installed on the ground floor, over the front bogie, is least affected by the coach natural modes, since this position is near to a node of the coach shape modes. Moreover, this point of the coach, being installed close to the secondary suspension, is more susceptible to the bogie natural mode. 


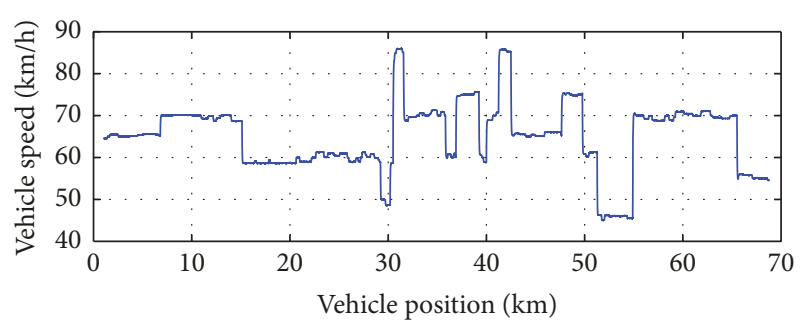

(a)

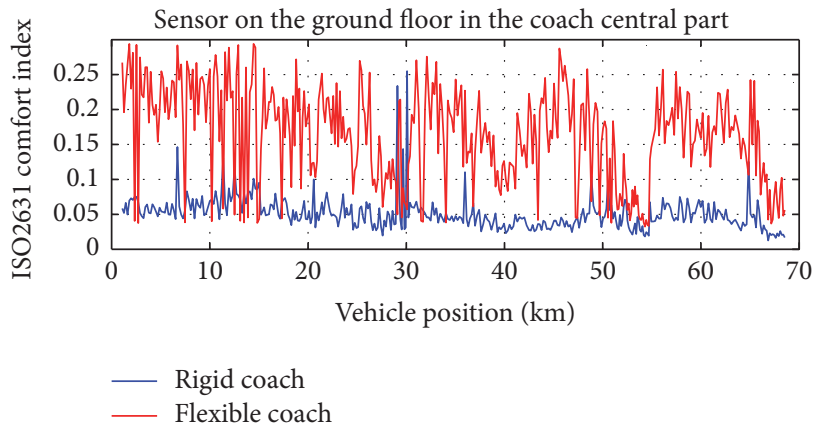

(c)

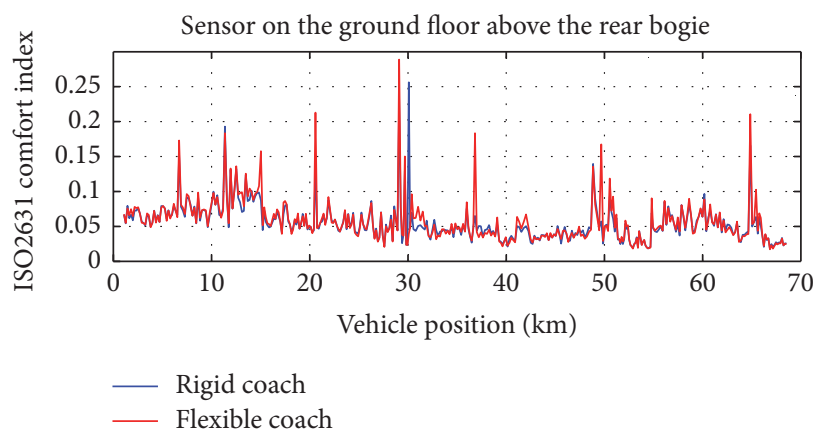

(b)

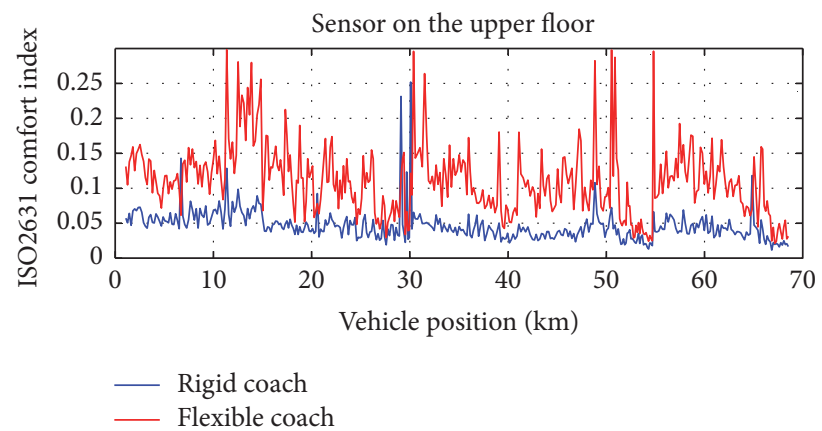

(d)

FIGURE 24: Comfort index evaluated on different points of the coach.

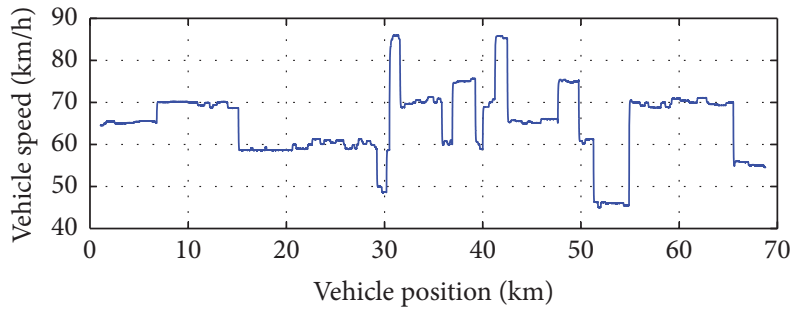

(a)

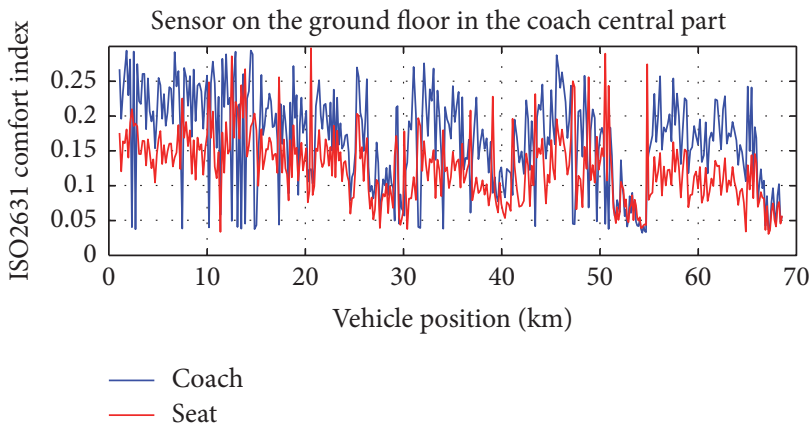

(b)

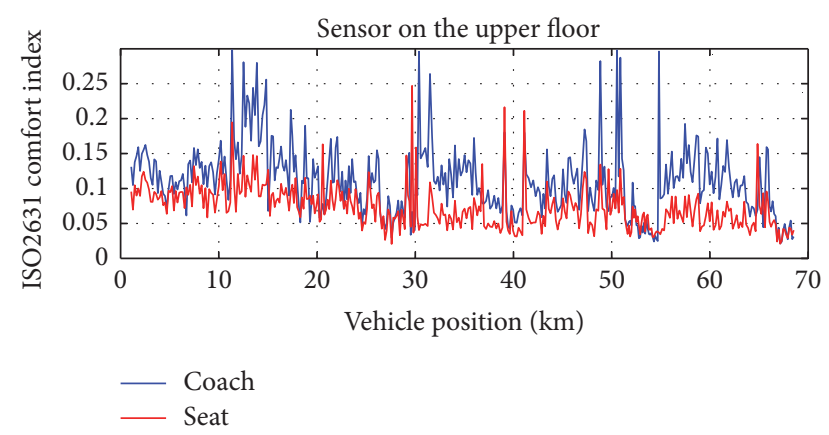

(c)

FIGURE 25: Comparison of the comfort index calculated on the coach and on the seat, on the ground floor (b), and on the upper floor (c).

Figure 25 shows the effect of the seat on the comfort level perceived by the passenger. The results relative to this comparison have been obtained only for the model with flexible coach. In this case, the seat allows, in general, an improvement of the comfort index if we consider the central ground floor and the upper floor. The seat has, instead, little benefit if we consider the sensor over the rear bogie, where, in some sections of the track, the comfort index is worse on the seat than on the floor. This behavior can be explained considering the seat transfer function (shown in Figure 14) that amplifies the frequency range $2-5 \mathrm{~Hz}$ and cut the frequencies higher than $7 \mathrm{~Hz}$. The seat is then able to filter the natural modes of the coach, but amplifying the frequency range typical of the bogie natural modes. 
TABLE 9: Average values of the comfort index in different track sections.

\begin{tabular}{|c|c|c|c|c|c|c|}
\hline \multirow{2}{*}{ Section } & \multicolumn{3}{|c|}{ Ground floor } & \multicolumn{3}{|c|}{ Upper floor } \\
\hline & Floor & Seat & $\Delta \%$ & Floor & Seat & $\Delta \%$ \\
\hline $0-10 \mathrm{~km}$ & 0.2203 & 0.1567 & $29 \%$ & 0.1218 & 0.0925 & $24 \%$ \\
\hline $10-20 \mathrm{~km}$ & 0.1857 & 0.16 & $14 \%$ & 0.1512 & 0.0959 & $37 \%$ \\
\hline $20-30 \mathrm{~km}$ & 0.1484 & 0.1181 & $20 \%$ & 0.0919 & 0.0762 & $17 \%$ \\
\hline $30-40 \mathrm{~km}$ & 0.1634 & 0.1150 & $30 \%$ & 0.1134 & 0.0612 & $46 \%$ \\
\hline $40-50 \mathrm{~km}$ & 0.1704 & 0.1317 & $23 \%$ & 0.1048 & 0.07 & $33 \%$ \\
\hline $50-60 \mathrm{~km}$ & 0.1250 & 0.1012 & $19 \%$ & 0.0978 & 0.0590 & $40 \%$ \\
\hline $60-70 \mathrm{~km}$ & 0.1364 & 0.0888 & $35 \%$ & 0.0833 & 0.0536 & $36 \%$ \\
\hline
\end{tabular}

Table 9 compares the average values obtained on the floor and on the seat considering track sections of $10 \mathrm{~km}$, so that the benefit of the seat can be better analyzed. The use of the seat leads to an improvement of the comfort of $14-35 \%$ on the ground floor and $17-46 \%$ on the upper floor.

The results shown in this section allow concluding that the vehicle developed within the CARITAS project is able to guarantee a very high level of comfort for both standing and sitting passengers. The design of the seat allowed reaching a further improvement of the comfort level.

\section{Conclusions}

The paper shows the numerical model of a vehicle for the transport of people with reduced mobility. The work has been developed in the CARITAS project within the national research program "Industria 2015." The numerical model has been used to analyze and optimize the performance of the vehicle in terms of comfort. The results prove that the coach flexibility plays an important role in the comfort level of the vehicle and cannot be neglected. For this reason, the FEM model of the coach has been integrated in the MB model of the vehicle in order to evaluate the index of comfort of the vehicle in different points of the structure. The paper also analyzes the effect of the seat, which is really important when considering passengers with reduced mobility. The seat has been simulated as a force element with frequency dependent behavior, which has been calculated experimentally after optimizing the design of the seat.

The vehicle model has been simulated on a real track with irregularities measured on a real line, in order to evaluate its realistic performance in terms of comfort. The results allow concluding that the coach prototype, developed within the project, guarantees a high level of comfort especially to seated passengers.

\section{Conflicts of Interest}

The authors declare that there are no conflicts of interest regarding the publication of this paper.

\section{Acknowledgments}

This research has been developed within the CARITAS project in the Italian National Research Program "Industria 2015."

\section{References}

[1] G. Diana, F. Cheli, A. Collina, R. Corradi, and S. Melzi, "The development of a numerical model for railway vehicles comfort assessment through comparison with experimental measurements," Vehicle System Dynamics, vol. 38, no. 3, pp. 165$183,2002$.

[2] S. K. Sharma and A. Kumar, "Ride comfort of a higher speed rail vehicle using a magnetorheological suspension system," Proceedings of the Institution of Mechanical Engineers, Part K: Journal of Multi-body Dynamics, vol. 0, no. 0, pp. 1-17, 2017.

[3] M. H. Kargarnovin, D. Younesian, D. Thompson, and C. Jones, "Ride comfort of high-speed trains travelling over railway bridges," Vehicle System Dynamics, vol. 43, no. 3, pp. 173-199, 2005.

[4] M. Spiryagin, C. Cole, Y. Q. Sun, M. McClanachan, V. Spiryagin, and T. McSweeney, Design and Simulation of Rail Vehicles, CRC Press, 2014.

[5] M. Dumitriu, "A new passive approach to reducing the carbody vertical bending vibration of railway vehicles," Vehicle System Dynamics, vol. 55, no. 11, pp. 1787-1806, 2017.

[6] J. Zhou, R. Goodall, L. Ren, and H. Zhang, "Influences of car body vertical flexibility on ride quality of passenger railway vehicles," Proceedings of the Institution of Mechanical Engineers, Part F: Journal of Rail and Rapid Transit, vol. 223, no. 5, pp. 461471, 2009.

[7] N. Zampieri, N. Bosso, and A. Gugliotta, "A Study of the Comfort Level of a Railway Vehicle for Reduced Mobility Passengers," in Proceedings of the The Fourteenth International Conference on Civil, Structural and Environmental Engineering Computing, 32 pages, Civil-Comp Press, Stirlingshire, UK, 2013.

[8] E. Kardas-Cinal, "Ride comfort for various passenger positions in a railway vehicle - Simulation study," Archives of Transport, vol. 22, no. 2, pp. 189-199, 2010.

[9] P. F. Carlbom, "Combining MBS with FEM for Rail Vehicle Dynamics Analysis," Multibody System Dynamics, vol. 6, no. 3, pp. 291-300, 2001.

[10] K. V. Gangadharan, C. Sujatha, and V. Ramamurti, "Experimental and analytical ride comfort evaluation of a railway coach," in Proceedings of the A conference \& exposition on structural dynamics (SEM ORG IMAC XXII), pp. 1-15, Dearborn, Michigan, 2004.

[11] M. Götsch and M. Sayir, "Simulation of the riding comfort of railway coaches," Vehicle System Dynamics, vol. 37, supplement 1, pp. 630-640, 2002.

[12] C. Braccesi, F. Cianetti, and A. Elia, "Motion sickness. Part II: experimental verification on the railways of a model for predicting motion sickness incidence," International Journal of 
Human Factors Modelling and Simulation, vol. 2, no. 3, p. 188, 2011.

[13] P. Carlbom and M. Berg, "Passengers, seats and carbody in rail vehicle dynamics," Vehicle System Dynamics, vol. 37, supplement 1, pp. 290-300, 2003.

[14] V. Barone, D. W. Mongelli, and A. Tassitani, "Definition of An On-Board Comfort Index CI(rail) for the Railway Transport," Journal of Advanced Transportation, vol. 2017, pp. 1-11, 2017.

[15] "ISO 2631-1 Mechanical vibration and shock," in Evaluation of Human Exposure to Whole-Body Vibration, 1997.

[16] S. Pankoke and A. Siefert, "Virtual simulation of static and dynamic seating comfort in the development process of automobiles and automotive seats: Application of finite-elementoccupant-model CASIMIR," SAE Technical Papers, 2007.

[17] M. A. Ksiazek and Ł. Łacny, "A comparison of the human bodyseat model responses to several types of impulse excitations," Journal of Theoretical and Applied Mechanics, vol. 52, no. 3, pp. 839-845, 2014.

[18] G. S. Paddan and M. J. Griffin, "Effect of seating on exposures to whole-body vibration in vehicles," Journal of Sound \& Vibration, vol. 253, no. 1, pp. 215-241, 2002.

[19] S. D. Smith, J. A. Smith, and R. J. Newman, "Vibration Transmissibility Characteristics of Occupied Suspension Seats," Defense Technical Information Center, 2006, Report AFRLHE-WP-TR-2006-0133.

[20] N. Zampieri, N. Bosso, and A. Gugliotta, "Design of a Dynamic Testing Machine for Railway Seats," in Proceedings of the The Fourteenth International Conference on Civil, Structural and Environmental Engineering Computing, 36 pages, Civil-Comp Press, Stirlingshire, UK, 2013.

[21] N. Bosso, A. Gugliotta, and N. Zampieri, "Dynamic Test Rig for Railway Seats: Design and Experimental Characterisation," International Journal of Railway Technology, vol. 3, no. 3, pp. 5576, 2014.

[22] ORE B176 Preliminary Studies And Specifications, vol. 1, 1989.

[23] 2017, Dassault Systemes Simulia Corp, Simpack Documentation, D.23.3.8 Normal Force Calculation.

[24] J. J. Kalker, "A Fast Algorithm for the Simplified Theory of Rolling Contact," Vehicle System Dynamics, vol. 11, no. 1, pp. 1-13, 1982.

[25] 2005, ISO 8041 Human response to vibration - measuring instrumentation.

[26] A. N. Rimell and N. J. Mansfield, "Design of digital filters for frequency weightings required for risk assessments of workers exposed to vibration," Industrial Health, vol. 45, no. 4, pp. 512519, 2007.

[27] 1994, UIC 513 Guidelines for evaluating passenger comfort in relation to vibration in railway vehicles. 


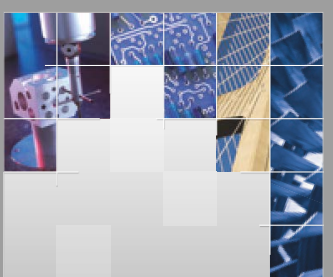

\section{Enfincering}
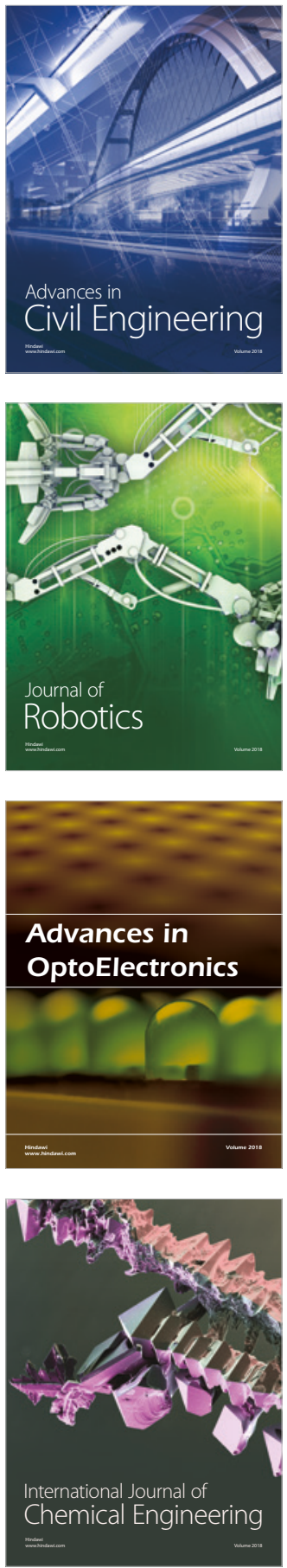

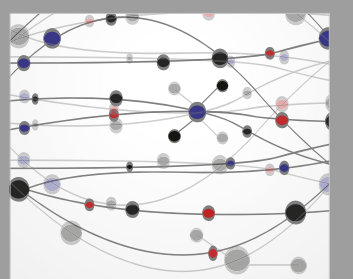

\section{Rotating \\ Machinery}

The Scientific World Journal

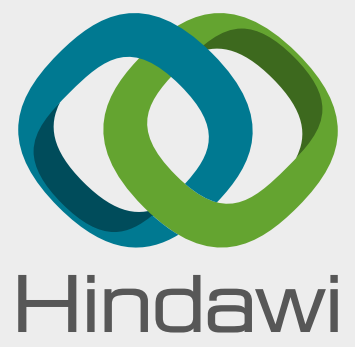

Submit your manuscripts at

www.hindawi.com
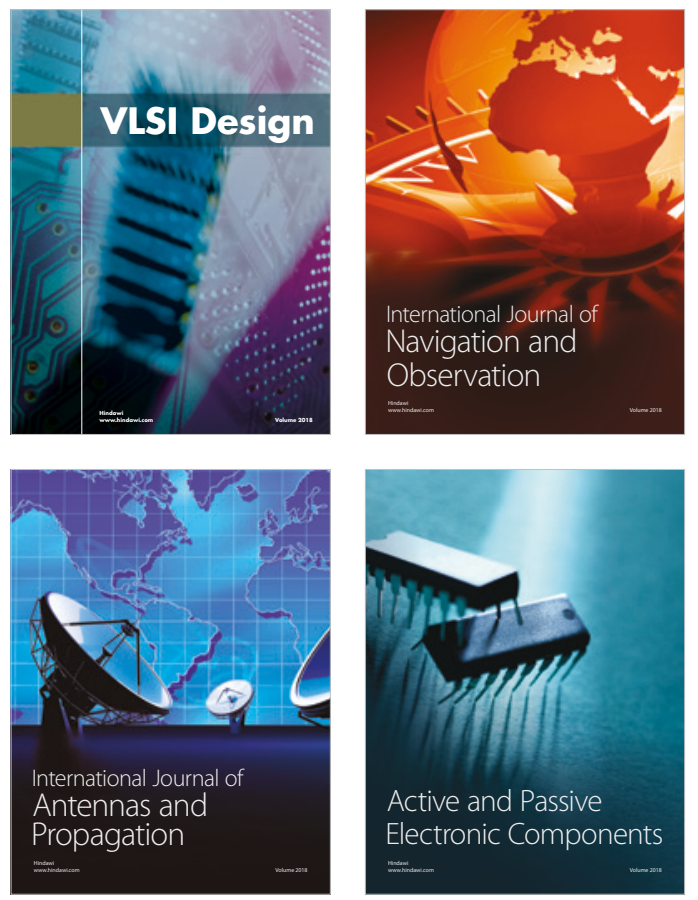
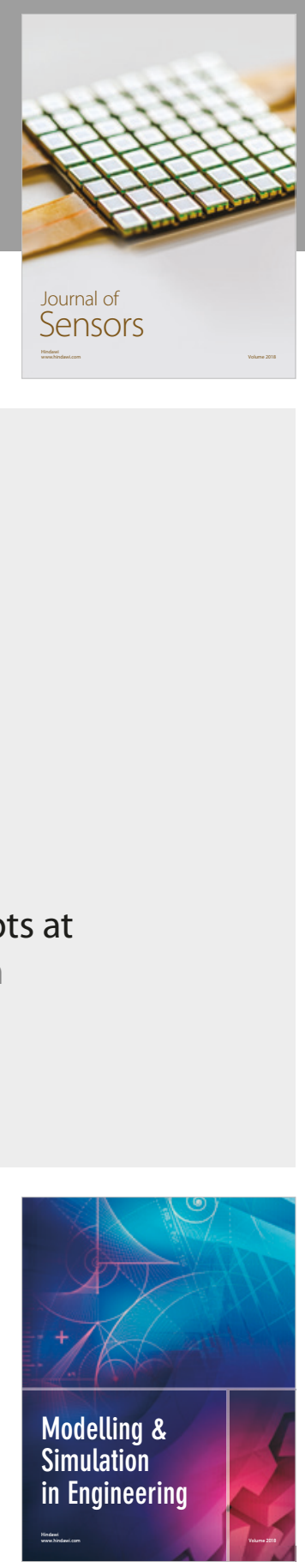

\section{Advances \\ Multimedia}
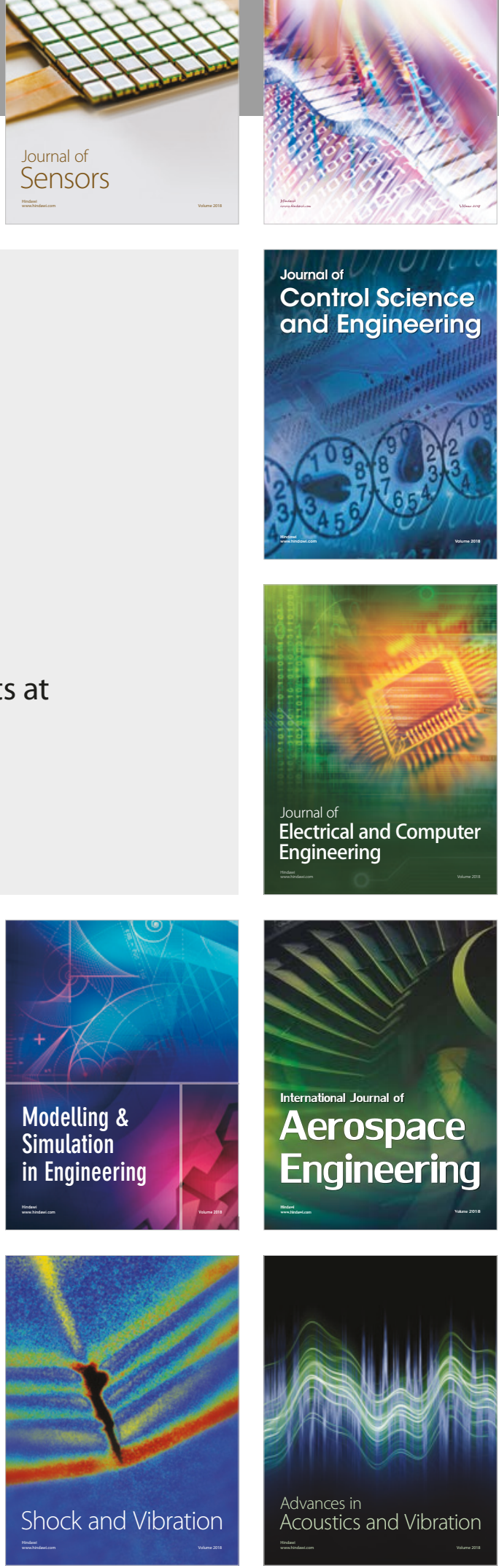